\title{
A Kolsky Haiku
}

Jamie Kimberley ${ }^{1}$

Accepted: 26 October 2020 / Published online: 23 November 2020

(c) Society for Experimental Mechanics, Inc 2020

I had the good fortune to spend several years working with KT as a postdoctoral fellow. In those years I came to appreciate many aspects of KT's personality and his broad interests. I can best describe KT as an extremely bright, thoughtful, and compassionate person who cares deeply about his students, post-docs, colleagues, and family. KT is a bit of a Renaissance man, with deep personal interest in topics such as astronomy and poetry. KT tries to instill the importance of a broad education in all those who surround him and has gone as far as starting every group meeting by reading a poem, and requiring all of his $\mathrm{PhD}$ students to develop a creative interpretation of their PhD. During my time in his group, I witnessed interpretations such as a painting of crack-tip stress fields, Claymation describing the deformation gradient, sculptures of dislocations, and Bollywood-inspired dance routines. Since I completed my $\mathrm{PhD}$ elsewhere, I never developed a creative interpretation of it. However, I have come to appreciate the importance of a broad view. Poetry is not my "thing", but I thought that a poem would be a fitting tribute in honor of KT's $60^{\text {th }}$ birthday. So as a small token of my appreciation to KT for his years of support, mentorship, and friendship-from nearby the bottom of my heart-I present a "Kolsky Haiku".

Swift slender bars move.

Quickly assessing response.

What is your strength?

Publisher's Note Springer Nature remains neutral with regard to jurisdictional claims in published maps and institutional affiliations.
Jamie Kimberley

Jamie.kimberley@nmt.edu

1 Department of Mechanical Engineering, New Mexico Institute of Mining and Technology, Socorro, NM 87801, USA 